\title{
An ocean-atmosphere index for ENSO and its relation to Indian monsoon rainfall
}

\author{
A A MUNOT and G B Pant \\ Indian Institute of Tropical Meteorology, Pune 411008, India
}

\begin{abstract}
An Ocean-Atmosphere Index (OAI) for ENSO is developed using data on Southern Oscillation Index (SOI) and sea surface temperature (SST) over eastern equatorial Pacific. Seasonal values of OAI, SOI and SST have been computed for the seasons September-October-November (SON), December-JanuaryFebruary (DJF), March-April-May (MAM) and June-July-August (JJA). Similarly SON to DJF, DJF to MAM, MAM to JJA and JJA to SON tendencies have been worked out for SOI, SST and OAI. The relationships between Indian Monsoon Rainfall (IMR) and SOI/SST/OAI, (i) for the seasons SON, DJF and MAM before and after the monsoon and JJA concurrent with the monsoon and (ii) for SON to DJF and DJF to MAM tendencies before and after the monsoon, and MAM to JJA tendency concurrent with the monsoon have been explored. It is found that IMR is more influenced by SOI before the monsoon than it is influenced by SST before the monsoon and IMR affects SST after monsoon more strongly than it affects SOI after the monsoon. It is also observed that DJF to MAM tendencies for SOI, SST and OAI before monsoon are significantly related to IMR, among which the relationship between IMR and DJF to MAM tendency for OAI is the best.
\end{abstract}

\section{Introduction}

The Indian monsoon rainfall exhibits considerable interannual variability. ENSO is one of the most important global factors associated with fluctuations of Indian monsoon rainfall (IMR). A growing interest in understanding and estimating the monsoon rain over India has resulted in many studies on the relationship between IMR and ENSO. Some of the noteworthy studies are, Angell (1981); Shukla and Paolino (1983); Mooley and Parthasarathy (1984); Mooley et al (1985); Elliot and Angell (1987, 1988). Shukla and Paolino (1983) brought out that a highly significant inverse relationship exists between IMR and Darwin pressure tendency from DJF to MAM before the monsoon. Mooley and Munot (1993), found stable and significant relation of IMR with (i) sea surface temperature (SST) tendency from DJF to MAM after and before the monsoon, the former over whole period and latter over some component periods (ii) southern oscillation index (SOI) tendency from DJF to MAM both before and after the monsoon, for some component periods. Most of these studies in general indicate that relationships between IMR and SOI/SST for different seasons/tendencies are not stable. There is always variation in the relationship with regard to strength and stability. The main objective of this study is therefore to develop an index representing in some sense the ocean-atmosphere interaction, Ocean-Atmosphere Index (OAI), which may be more useful for prediction of IMR using SOI and SST data, and study its relationship with IMR for different seasons/tendencies and to compare (IMR, SOI), (IMR, SST) and (IMR, OAI) relationships.

\section{Data used}

The following data sets have been used in this study:

- Indian monsoon rainfall data (June to September) for the period 1871-1990 are taken from Parthasarathy et al (1995).

Keywords. Southern oscillation index; sea surface temperature; ocean-atmosphere index; correlation coefficients. 
- Darwin monthly mean sea level pressure data for the period 1871-1990 are taken as a measure of Southern Oscillation Index.

- Seasonal anomalies of SST as compiled by Angell (1981), for the large area of the eastern equatorial Pacific, $0^{\circ}-10^{\circ} \mathrm{S}$ and $180^{\circ}-80^{\circ} \mathrm{W}$.

The seasonal values of SOI and SST are computed for the seasons December (of previous year)-JanuaryFebruary (DJF), March-April-May (MAM), JuneJuly-August (JJA) and September-October-November (SON). Also SST/SOI tendencies are computed as follows:

$$
\begin{aligned}
& \mathrm{SOIT} 0 / \mathrm{SSTT} 0=(\mathrm{SOI} / \mathrm{SST})_{\mathrm{FSON}^{-}}(\mathrm{SOI} / \mathrm{SST})_{\mathrm{CJJA}} \\
& \mathrm{SOIT}-1 / \mathrm{SSTT}-1=(\mathrm{SOI} / \mathrm{SST})_{\mathrm{PMAM}^{-}}-(\mathrm{SOI} / \mathrm{SST})_{\mathrm{PDJF}} \\
& \mathrm{SOIT}-2 / \mathrm{SSTT}-2=(\mathrm{SOI} / \mathrm{SST})_{\mathrm{PDJF}}-(\mathrm{SOI} / \mathrm{SST})_{\mathrm{PSON}} \\
& \mathrm{SOIT} 1 / \mathrm{SSTT} 1=(\mathrm{SOI} / \mathrm{SST})_{\mathrm{FDJF}^{-}}(\mathrm{SOI} / \mathrm{SST})_{\mathrm{FSON}} \\
& \mathrm{SOIT} 2 / \mathrm{SSTT} 2=(\mathrm{SOI} / \mathrm{SST})_{\mathrm{FMAM}^{-}}-(\mathrm{SOI} / \mathrm{SST})_{\mathrm{FDJF}}
\end{aligned}
$$

The letters $\mathrm{P}, \mathrm{C}, \mathrm{F}$ before the season indicate respectively the season preceding concurrent JJA, concurrent JJA and the season following the concurrent JJA. The season JJA has been considered as concurrent with IMR.

\section{Relationship with all-India rainfall}

\subsection{Southern oscillation index}

In order to understand the association between the IMR and SOI for all the seasons and for all the tendencies the correlation coefficients (CCs) between the two series have been computed. The CCs are tabulated in table 1 which shows the following features as regards the SOI:

- CCs between IMR and SOI for the seasons PMAM, CJJA, FSON, FDJF and FMAM are negative and significant at $5 \%$ or $1 \%$ level of significance.

- The relationships between IMR and SOI for seasons after monsoon are stronger than the relationships between IMR and SOI for seasons before monsoon.

- There is a very strong negative relationship between IMR and SOIT-1 (significant at 1\% level).

- IMR is significantly related to SOIT2, the relationship is positive (significant at 5\% level).

- SOIT-1 is better related to IMR than SOI for any season before monsoon.

\subsection{Sea surface temperature}

The CCs between IMR and SST for all the seasons and for all the tendencies have been computed and tabulated in table 1 which shows the following important features:
- CCs between IMR and SST for the seasons CJJA, FSON, FDJF and FMAM are negative and significant at $1 \%$ level.

- There is a strong negative relationship between IMR and SSTT-1 (significant at 1\% level) and a strong positive relationship between IMR and SSTT2 (significant at 1\% level).

- SSTT-1 is better related to IMR than SST for any season before the monsoon.

If we compare the correlations of IMR with SOI and SST (table 1) it is observed that (i) SOI for PMAM season is better related to IMR than SST for PMAM season is related to IMR; (ii) relationships between IMR and SST for season FSON and FDJF are better than the relationships between IMR and SOI for the seasons FSON and FDJF respectively; (iii) SOIT-1 is better related to IMR than SSTT-1 is related to IMR; (iv) SSTT2 is better related to IMR than SOIT2 is related to IMR.

Thus, it can be concluded that IMR is more influenced by SOI before monsoon than it is influenced by SST before monsoon and it affects SST after monsoon more strongly than it affects SOI after monsoon, thus conjecturing that the monsoons are associated with the atmospheric component of the Southern Oscillation related circulations and resulting into oceanic changes as a result of monsoon circulation.

\section{Preparation of ocean-atmosphere index}

The Ocean-Atmosphere Index (OAI) is prepared by assigning different weights to SOI and SST series for PDJF, PMAM, CJJA and FSON seasons. The OAI series for PDJF, PMAM, CJJA and FSON

Table 1. Correlation coefficients between IMR and SOI/SST/ OAI for different seasons/tendencies during 1871-1990.

\begin{tabular}{lccc}
\hline & SOI & SST & OAI \\
\hline Seasons & & & \\
PSON & 0.080 & 0.073 & 0.084 \\
PDJF & 0.065 & 0.093 & 0.085 \\
PMAM & $-0.296^{* *}$ & -0.164 & $-0.271^{* *}$ \\
CJJA & $-0.452^{* *}$ & $-0.443^{* *}$ & $-0.552^{* *}$ \\
FSON & $-0.576^{* *}$ & $-0.600^{* *}$ & $-0.649^{* *}$ \\
FDJF & $-0.514^{* *}$ & $-0.599^{* *}$ & $-0.601^{* *}$ \\
FMAM & $-0.299^{* *}$ & $-0.284^{* *}$ & $-0.345^{* *}$ \\
Tendencies & & & \\
PDJF-PSON & -0.021 & 0.038 & 0.004 \\
PMAM-PDJF & $-0.368^{* *}$ & $-0.312^{* *}$ & $-0.429^{* *}$ \\
FSON-CJJA & -0.179 & $-0.232^{*}$ & $-0.268^{* *}$ \\
FDJF-FSON & 0.084 & 0.001 & 0.066 \\
FMAM-FDJF & $0.218^{*}$ & $0.385^{* *}$ & $0.367^{* *}$ \\
\hline
\end{tabular}

Note: *Significant at $5 \%$ level; **Significant at $1 \%$ level. 
Table 2. Correlation coefficient between IMR and OAIT-1 for different weights to SST and SOI during 1871-1990.

\begin{tabular}{|c|c|c|}
\hline \multicolumn{2}{|c|}{ Weights } & \multirow[t]{2}{*}{ CC(IMR, OAIT-1) } \\
\hline$\overline{\mathrm{SST}}$ & SOI & \\
\hline 0.0 & 1.0 & -0.368 \\
\hline 0.1 & 0.9 & -0.385 \\
\hline 0.2 & 0.8 & -0.402 \\
\hline 0.3 & 0.7 & -0.417 \\
\hline 0.4 & 0.6 & -0.427 \\
\hline 0.5 & 0.5 & -0.429 \\
\hline 0.6 & 0.4 & -0.421 \\
\hline 0.7 & 0.3 & -0.403 \\
\hline 0.8 & 0.2 & -0.377 \\
\hline 0.9 & 0.1 & -0.345 \\
\hline 1.0 & 0.0 & -0.312 \\
\hline
\end{tabular}

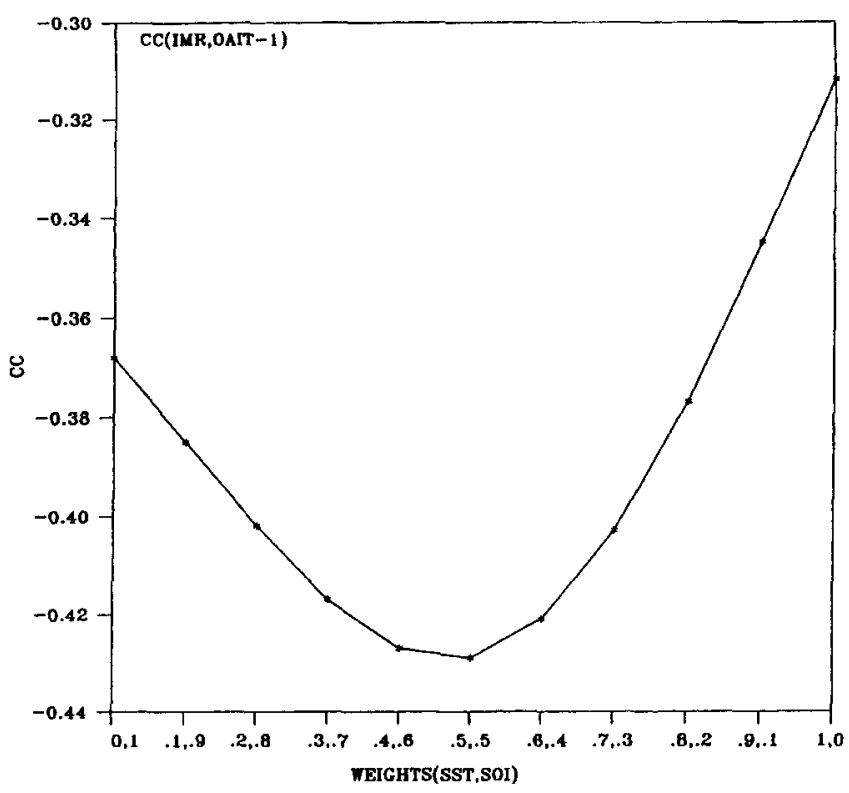

Figure 1. Correlation coefficient between IMR and OAIT-1 for different combination of weights to SST and SOI.

seasons are prepared for each pair of weights. As mentioned in section 2, the OAI series for PSON, PDJF, PMAM, CJJA, FSON, FDJF and FMAM seasons and OAIT-2, OAIT-1, OAIT0, OAIT1 and OAIT2 tendencies are then prepared. It is seen in earlier sections that SOIT-1/SSTT-1 are better related to IMR than any SOI/SST season before monsoon. In view of this OAIT-1 is selected as the test series. The numeric value of CC between IMR and OAIT-1 for the pair of weights for which it is maximum is used as the criteria for selecting the pair for preparation of OAI series, for all the above mentioned seasons and tendencies. To illustrate this point the CCs between IMR and OAIT- 1 for different combinations of weights are tabulated in table 2 and presented in figure 1. It is seen from table 2 that giving equal weights to SST and SOI (i.e. 0.5 and 0.5 respectively) the resulted OAIT- 1 is better related to IMR than SOIT-1 alone i.e. for weights $(0,1.0)$, SSTT-1 alone i.e. for weights $(1.0,0)$ and other combination of weights.

Thus the weights $(0.5,0.5)$ are the best among all the combinations. Therefore using this pair of weights to SST and SOI series, the OAI series for different seasons/tendencies are prepared.

\section{Relationship between IMR and OAI}

The CCs between IMR and OAI for the season PSON, PDJF, PMAM, CJJA, FSON, FDJF and FMAM and between IMR and OAI tendencies i.e. OAIT-2, OAIT1, OAIT0, OAIT1 and OAIT2 are tabulated in the last column of table 1 . This table shows that (i) OAI is better related to IMR for seasons CJJA, FSON, FDJF and FMAM than both SOI and SST are related to IMR for respective seasons. (ii) OAIT-1 is better related to IMR than both SOIT-1 and SSTT-1.

\subsection{Comparison between relationships of SOIT-1/SSTT-1/OAIT-1 and IMR}

As SOIT-1, SSTT-1 and OAIT-1 have got importance in forecasting subsequent Indian monsoon rainfall, the comparison is made between relationships of (IMR, SOIT-1) (IMR, SSTT-1) and (IMR, OAIT-1). It is seen from table 1 that the CC between IMR and SOIT-1 is -0.368 , CC between IMR and SSTT-1 is -0.312 and CC between (IMR, OAIT- 1 ) is -0.429 . Though all these relationships are negative and significant at $1 \%$ level, (IMR, OAIT-1) relationship is better than (IMR, SOIT-1) and (IMR,SSTT-1) relationships. To estimate how good these relationships are, the procedure used is as follows:

Let $x$ and $y$ be the variables for which the relationship is being considered. Four groups of values of the variables are obtained. These groups are labeled $A, B$, $C$ and $D$. $A$ contains values of $y$ in years of low values of $x, B$ contains values of $y$ in years of high values of $x$, $C$, contains values of $x$ in years of low values of $y$ and $D$ contains values of $x$ in years of high values of $y$. The criterion adopted for low and high values of a variable are about $16 \%$ lowest and $16 \%$ highest values respectively out of the total values of the variable within the period considered. Generally for a Gaussian distribution about $16 \%$ of the values of the variable are smaller than or equal to mean minus one standard deviation and about $16 \%$ are greater than or equal to mean plus one standard deviation. The variables we are concerned with are found to be Gaussian distributed. Hence this percentage has been adopted as a criterion for identifying low and high values of the variable. If the difference in the levels of the groups $A$ and $B$, as well as that in the levels of groups $C$ and $D$ are both significant at $5 \%$, the relationship between the two variables is classified as good, if significant at $1 \%$ 
Table 3. Examination of relationship between IMR and SOIT-1/SSTT-1/OAIT-1 during 1871-1990.

\begin{tabular}{|c|c|c|c|c|c|c|c|c|}
\hline \multicolumn{2}{|c|}{ Variables } & \multicolumn{4}{|c|}{ Mean of groups } & \multirow{2}{*}{$\begin{array}{l}\text { Inference from Mann- } \\
\text { Whitney test regarding } \\
\text { the level of groups }\end{array}$} & \multirow{2}{*}{$\begin{array}{c}\text { Level of } \\
\text { significance }\end{array}$} & \multirow{2}{*}{$\begin{array}{l}\text { Inference about } \\
\text { the relationship }\end{array}$} \\
\hline$x$ & $y$ & $A$ & $B$ & $C$ & $D$ & & & \\
\hline IMR & SOIT-1 & 0.494 & -0.436 & 0.538 & -0.686 & $\begin{array}{l}A>B \\
C>D\end{array}$ & $\begin{array}{c}1 \% \\
0.1 \%\end{array}$ & very good \\
\hline IMR & SSTT-1 & 0.361 & -0.346 & 0.316 & -0.835 & $\begin{array}{l}A>B \\
C>D\end{array}$ & $\begin{array}{l}5 \% \\
1 \%\end{array}$ & good \\
\hline IMR & OAIT-1 & 0.543 & -0.495 & 0.393 & -0.851 & $\begin{array}{l}A>B \\
C>D\end{array}$ & $\begin{array}{l}0.1 \% \\
0.1 \%\end{array}$ & excellent \\
\hline
\end{tabular}
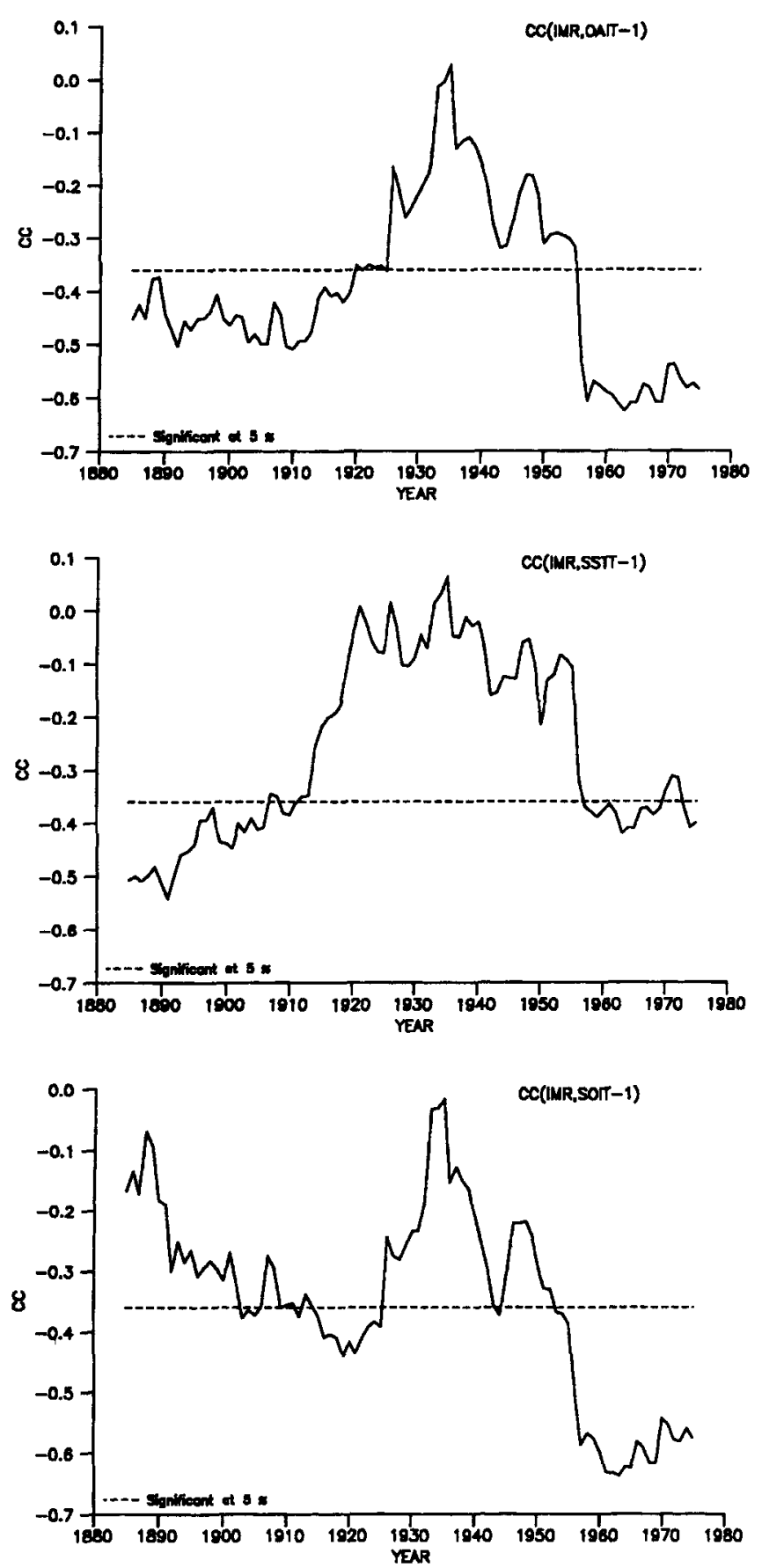

Figure 2. Correlation coefficient for sliding 30-year period between IMR and SOIT-1/ SSTT-1/OAIT-1. CCs are plotted against the middle year of the period. level the relationship between the two variables is classified as very good and if significant at $0.1 \%$ level the relationship between the two variables is classified as excellent. For testing the significance of the difference in the levels of the concerned groups, the Mann-Whitney test is used (for details see Mooley and Munot 1993).

The results of this analysis are tabulated in table 3 which clearly shows that there are good, very good and excellent relationships between (IMR, SSTT-1) (IMR, SOIT-1) and (IMR,OAIT-1) respectively.

To examine the stability of these relationships, 30year sliding correlation coefficients are calculated between OAIT-1/SSTT-1/SOIT-1 and IMR. The CCs are plotted against the central year of the sliding period (figure 2) which shows that the (IMR, OAIT-1) relationship is more stable than (IMR, SOIT1) and (IMR, SSTT-1) relationships. It means that though there is a variation in the relationship in course of time, OAIT-1 remains related to IMR for a longer period than SOIT-1/ SSTT-1 remains related to IMR.

\section{SOIT-1/SSTT-1/OAIT-1 during excess and deficient rainfall years}

It is clearly shown that SOIT-1, SSTT-1 and OAIT-1 are related to IMR. Among these three measures of ENSO, OAIT-1 is the most dominating one. In this section an attempt is made to study the effect of SOIT-1, SSTT-1 and OAIT-1 on IMR during excess and deficient rainfall years. For this, the procedure followed is as follows:

Identify excess and deficient rainfall years in IMR series using suitable criterion. The criterion used is that, if rainfall of $i$ th year is greater than or equal to mean plus one standard deviation, the year is called excess rainfall year and if rainfall of $i$ th year is less than or equal to mean minus one standard deviation, the year is called deficient rainfall year. There are 19 excess and 22 deficient rainfall years, during 1871-1990, in the IMR series. Composite means of SOIT-1, SSTT-1 and OAIT-1 for excess and deficient rainfall years are computed. The 
Table 4. Contrast between deficient rainfall year composite and excess rainfall year composite of SOIT-1/SSTT-1/OAIT-1 during 1871-1990.

\begin{tabular}{lcccc}
\hline Parameter & Deficient year mean $(A)$ & Excess year mean $(B)$ & Difference $(A-B)$ & $t$-value \\
\hline SOIT-1 & 0.494 & -0.436 & 0.930 & 2.945 \\
SSTT-1 & 0.361 & -0.346 & 0.707 & 2.302 \\
OAIT-1 & 0.543 & -0.495 & 1.038 & 3.395 \\
\hline
\end{tabular}

difference in the mean is tested by the $t$-test. The results are tabulated in table 4 which shows that there is very good contrast in OAIT-1 during excess and deficient rainfall years. The difference in the means is 1.038 and corresponding $t$-value is 3.395 which is significant at $1 \%$ level of significance. The contrast in excess/deficient rainfall years is more than that for both SOIT-1 and SSTT-1.

\section{Conclusions}

The following conclusion can be drawn from the above study.

- IMR is more influenced by SOI before monsoon than it is influenced by SST before monsoon and IMR affects SST after monsoon more strongly than it affects SOI after monsoon.

- DJF to MAM tendencies of SOI, SST and OAI before monsoon are significantly related to IMR.

- (IMR, OAIT-1) relationship is more stable compared to (IMR, SOIT-1) and (IMR, SSTT-1) relationships.

- Among the three relationships viz. (IMR, SOIT-1), (IMR, SSTT-1) and (IMR, OAIT-1), the (IMR, OAIT-1) relationship is the best.

\section{References}

Angell J K 1981 Comparison of variations in atmospheric quantities with sea surface temperature variation in equatorial eastern Pacific; Mon. Weather Rev. 109 230-243

Elliott W P and Angell J K 1987 The relation between Indian Monsoon Rainfall, the Southern Oscillation and hemispheric air and sea surface temperature: 1884-1984; J. Clim. \& Appl. Meteorol. 26 943-948

Elliott W P and Angell J K 1988 Evidence for changes in Southern Oscillation relationships during the last 100 years; J. Climate 1 729-737

Mooley D A and Parthasarathy B 1984 Indian summer monsoon rainfall and the east equatorial Pacific sea surface temperature; Atmosphere-Ocean 22 23-35

Mooley D A, Parthasarathy B and Sontakke N A 1985 Relationship between all India summer monsoon rainfall and southern oscillation/eastern equatorial Pacific Sea surface temperature; Proc. Indian Acad. Sci. (Earth Planet. Sci.) 94 199-210

Mooley D A and Munot A A 1993 Variation in the relationship of the Indian Summer monsoon rainfall with global factors; Proc. Indian Acad. Sci. (Earth Planet. Sci.) Special issue on Climate \& Global Warming) 102 89-104

Parthasarathy B, Munot A A and Kothawale D R 1995 Monthly and seasonal rainfall series for all-India, homogeneous regions and meteorological subdivisions: 1871-1994; IITM Research Report No. RR-065

Shukla J and Paolino D A Jr 1983 The southern oscillation and long range forecasting of summer monsoon rainfall over India; Mon. Weather Rev. 111 1830-1837 